\title{
Promoting Critical Thinking Through Troubleshooting Exercises in Funda- mental Electric Circuits Labs
}

\section{Mr. Joe Delvicario, University of Hartford}

Joe Delvicario began his college education with the University of Hartford's Audio Engineering and Technology program. He intended to work at a recording studio after graduating. However, while on this journey, the technology classes in this program inspired him to reorient his goals, towards a future in electrical engineering. It was a natural fit to take this newfound passion for electronics and begin sharing it with new students as an adjunct instructor at the University of Hartford, . At the same time, he began to pursue a Masters in Electrical and Computer Engineering and is looking forward to continuing a future in Electronics.

\section{Dominick Gerard Lauria, University of Hartford}

Dominick Lauria is currently an adjunct professor and graduate student in Electrical Engineering at the University of Hartford. He earned a BS degree in Audio Engineering Technology from the University of Hartford. He has two years of industry experience including: rigid-flex PCB design for submarine communications systems and professional audio equipment repair and manufacturing. Dominick Lauria's research interests include: audio equipment design, $\mathrm{PCB}$ design and manufacturing, communication systems, and renewable energy storage systems.

\section{Dr. Patricia Mellodge, University of Hartford}

Patricia Mellodge is an Associate Professor of Electrical and Computer Engineering at the University of Hartford. She received a B.S. in Electrical Engineering from the University of Rhode Island. Her graduate work was completed at Virginia Tech where she received an M.S. in Mathematics and an M.S. and Ph.D. in Electrical Engineering.

\section{Dr. Ying Yu, University of Hartford}

Dr. Ying Yu received her B.Eng. from Fudan University, Shanghai, China, in 2000. She received her M.S. and Ph.D. in Electrical Engineering from Brown University, R.I., USA, in 2003 and 2007, respectively. Currently, she is teaching as an associate professor of the S. I. Ward Department of Electrical and Computer Engineering at the University of Hartford. Her current research interests are audio and speech signal processing, promoting critical thinking through the engineering curriculum, promoting diversity and inclusion in the academic environment, and teaching with new educational methods, including peer instruction, personal response systems, video games, and state-of-the-art CAD tools. 


\title{
Promoting critical thinking through troubleshooting exercises in fundamental electric circuits labs
}

\begin{abstract}
This paper presents a study conducted in the fall semester of 2017 that aimed to promote students' critical thinking through a series of newly-designed troubleshooting exercises embedded in fundamental DC electric circuits labs for engineering technology first-year students.
\end{abstract}

Three circuit troubleshooting sessions were purposefully designed and embedded throughout the course of the semester. For each session, students investigated several different scenarios in which the given circuits were not working. The complexity of the given circuits increased as the semester progressed with the increasing theoretical knowledge of the students. Each scenario challenged students to identify and solve one or more unknown faults in the circuit. After each session, instructors used students' troubleshooting plan, reflective discussions, and conclusions in their reports to evaluate students' critical thinking skills. A newly-designed critical thinking rubric refined for circuits troubleshooting was distributed to all instructors for assessment purpose.

According to the instructors' evaluation of students' troubleshooting reports, about $38 \%$ of students who completed all troubleshooting activities and assignments showed significant improvement in their troubleshooting skills. According to the student surveys, about $86 \%$ of students agree or strongly agree that troubleshooting exercises helped them improve their troubleshooting skills; about $83 \%$ of students agree or strongly agree that troubleshooting exercises helped them improve their critical thinking skills; about $53 \%$ of students agree or strongly agree that troubleshooting exercises helped them perform better in other labs and projects; about $56 \%$ of students agree or strongly agree that troubleshooting exercises helped them better understand the theory introduced in the lectures.

Sample troubleshooting exercises, troubleshooting rubric, detailed student performance evaluation data, students' and instructors' feedback, and future plans for improvement are presented.

* Appearance of authors is in alphabetical order by last name.

\section{Introduction}

According to a national survey of business and nonprofit leaders commissioned by AACU [1]: $93 \%$ of employers surveyed say that "a demonstrated capacity to think critically, communicate clearly, and solve complex problems is more important than [a candidate's] undergraduate major." The same survey also indicates that more than $75 \%$ of those surveyed say they want more emphasis on five key areas including: critical thinking, complex problem solving, written and oral communication, and applied knowledge in real-world settings. 
As part of the larger goal to better prepare students for career success and personal development, improving students' critical thinking ability has been a significant initiative of the University of Hartford's strategic plan since 2014. In the fall semester of 2017, we implemented a coordinated large-scale project that aimed to promote students' critical thinking through a series of newlydesigned troubleshooting exercises embedded in all fundamental DC electric circuits labs for engineering technology first-year students. This impacted three major engineering technology programs (Audio Engineering Technology, Computer and Electronic Engineering Technology, and Electromechanical Engineering Technology), totaling 66 first-year students.

We decided to use the classic definition of critical thinking from Scriven 1996 [2] for the purpose of our project: "Critical thinking is the intellectually disciplined process of actively and skillfully conceptualizing, applying, analyzing, synthesizing, and/or evaluating information gathered from, or generated by, observation, experience, reflection, reasoning, or communication, as a guide to belief and action."

Our motivation in introducing these troubleshooting exercises in the first-year fundamental DC circuits labs is to provide students with fresh challenges, help them improve their troubleshooting skills, critical thinking skills, help them perform better in other labs, projects and better understand the theory introduced in the lectures.

\section{Project Implementation}

The DC electric circuits course composes of 3 credit lecture and 1 credit ( 3 hours) lab. Three circuit troubleshooting sessions were purposefully designed and embedded throughout the course of the semester. See Table 1 for complete lab schedule.

Table 1: Lab Schedule for DC Electrical Fundamentals Lab

\begin{tabular}{|c|c|c|}
\hline Lab Index & Format & Subject \\
\hline Lab 1 & Typical Lab* & Laboratory Meters and Power Supply \\
\hline Lab 2 & Typical Lab & Measurement of Resistance \\
\hline Lab 3 & Typical Lab & Ohm's Law \\
\hline Lab 4 & Typical Lab & Power in DC Circuits \\
\hline Lab 5 & Typical Lab & Series Circuits \\
\hline Lab 6 & Troubleshooting 1 & The Voltage Divider \\
\hline Lab 7 & Typical Lab & Parallel Circuits \\
\hline Lab 8 & Typical Lab & Troubleshooting of Parallel Circuits \\
\hline Lab 9 & Troubleshooting 2 & Voltage Divider Project Design and \\
Implementation
\end{tabular}

For each session, teams of two students investigated multiple pre-built circuits with various scenarios of potential faults. The complexity of the given circuits increased as the semester 
progressed with the increasing theoretical knowledge of the students. Each scenario challenged students to identify and solve one or more unknown faults in the circuit. See Figures 1, 2, and 3 for the complete schematics used in the troubleshooting sessions and the various scenarios presented to each student team. In order to more effectively assess individual student's learning and increase the efficacy of the troubleshooting exercises [3], students were required to submit individual troubleshooting plans and post-lab reports. After each session, instructors used students' troubleshooting plans, reflective discussions, and conclusions in their reports to evaluate students' critical thinking skills.

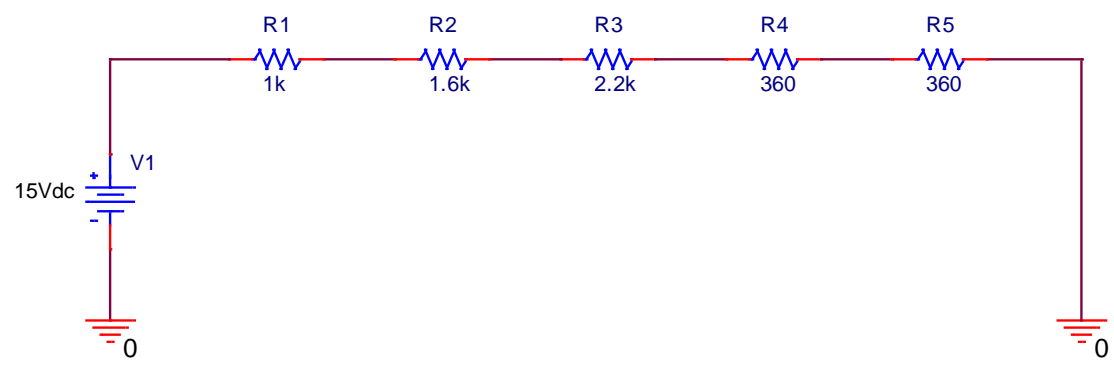

Figure 1: Schematic for Troubleshooting Session 1: Series Circuit (scenario 1: Open circuit; scenario 2: Bad wire; scenario 3: Shorted resistor; scenario 4: Misconnected ground wire)

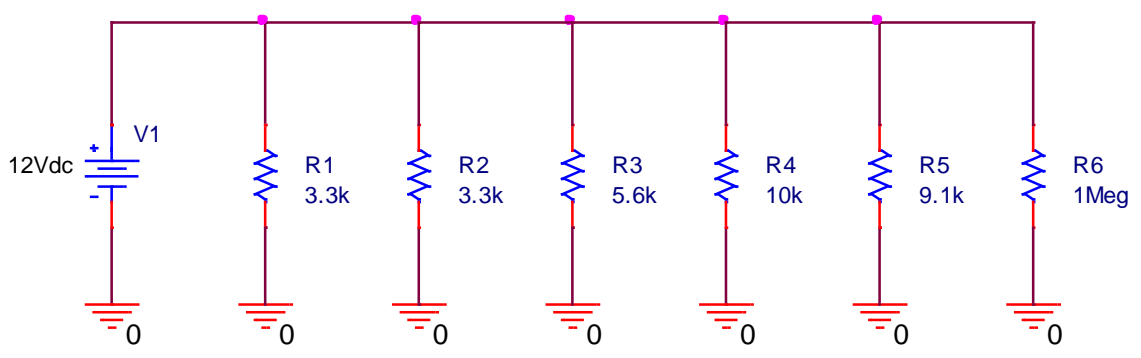

Figure 2: Schematic for Troubleshooting Session 2: Parallel Circuit (scenario 1: Broken wire and incorrect $R 5$ value; scenario 2: Incorrect $R 2$ value and incorrect $R 6$ value; scenario 3: Incorrect $R 4$ value, open R6, incorrect R6 value)

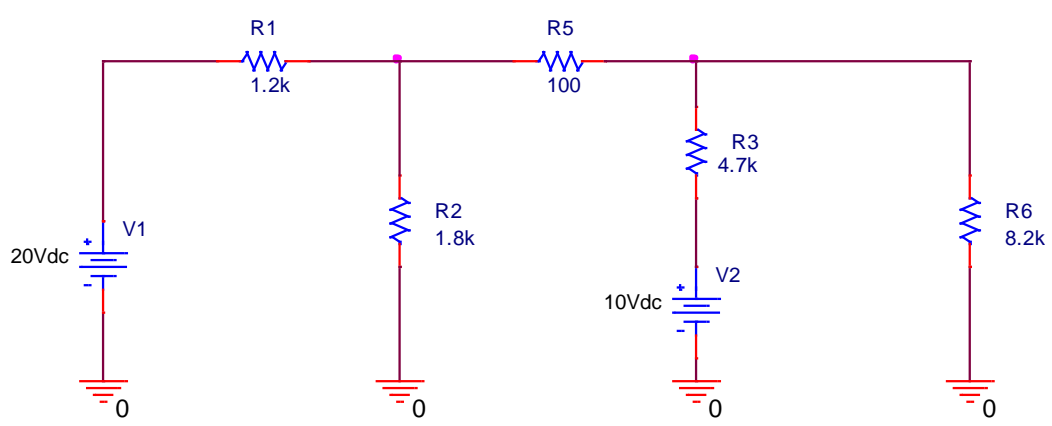

Figure 3: Schematic for Troubleshooting Session 3: Series-Parallel Circuit with Two Power Sources (scenario 1: Various incorrect resistors and misconnections; scenario 2: No faults)

A newly-designed critical thinking rubric refined for circuits troubleshooting were distributed to all instructors for assessment purpose. See Table 2 for the complete troubleshooting rubric. In order to discourage thoughtless actions such as haphazardly swapping components and wires, 
students were required to generate a troubleshooting plan as part of the prelab exercise. To apply critical thinking for the purpose of circuit troubleshooting, students were asked to:

- Clearly identify and accurately summarize the problem;

- Develop multiple hypotheses as to why the circuits are not working;

- Formulate ways to gather more evidence and data to examine the hypotheses using knowledge of electric circuits;

- Form conclusions and execute solutions.

In their reports, students were required to include their troubleshooting plans and detailed documented outcomes of each procedure and subsequent actions.

Table 2: Troubleshooting Report Rubric

\begin{tabular}{|c|c|c|c|c|}
\hline $\begin{array}{l}\text { Criteria } \\
\text { Performance } \\
\text { Indicator }\end{array}$ & $\begin{array}{l}\text { Exemplary } \\
(8.5-10)\end{array}$ & $\begin{array}{c}\text { Satisfactory } \\
(6.5-8)\end{array}$ & $\begin{array}{c}\text { Developing } \\
\quad(4-6)\end{array}$ & $\begin{array}{l}\text { Unsatisfactory } \\
\quad(0-3.5)\end{array}$ \\
\hline $\begin{array}{c}\text { Identify and } \\
\text { summarize the } \\
\text { problem; }(25 \%)\end{array}$ & $\begin{array}{l}\text { The problem is } \\
\text { clearly } \\
\text { identified and } \\
\text { accurately } \\
\text { summarized. }\end{array}$ & $\begin{array}{l}\text { The problem is } \\
\text { mostly } \\
\text { identified and } \\
\text { summarized } \\
\text { fairly clearly } \\
\text { and accurately. }\end{array}$ & $\begin{array}{l}\text { The problem is } \\
\text { somewhat } \\
\text { identified and } \\
\text { summarized but } \\
\text { lacks clarity and } \\
\text { accuracy. }\end{array}$ & $\begin{array}{l}\text { The problem is } \\
\text { not identified } \\
\text { and summarized } \\
\text { with clarity or } \\
\text { accuracy. }\end{array}$ \\
\hline $\begin{array}{l}\text { Develop } \\
\text { hypotheses as to } \\
\text { why the circuits } \\
\text { are not working; } \\
\quad(25 \%)\end{array}$ & $\begin{array}{l}\text { An exhaustive } \\
\text { list of } \\
\text { appropriate } \\
\text { hypotheses were } \\
\text { developed with } \\
\text { detail. }\end{array}$ & $\begin{array}{l}\text { Three or four } \\
\text { appropriate } \\
\text { hypotheses } \\
\text { were developed } \\
\text { with detail. }\end{array}$ & $\begin{array}{c}\text { One or two } \\
\text { appropriate } \\
\text { hypotheses } \\
\text { were developed } \\
\text { with detail. }\end{array}$ & $\begin{array}{c}\text { No appropriate } \\
\text { hypothesis were } \\
\text { developed. }\end{array}$ \\
\hline $\begin{array}{l}\text { Formulate ways to } \\
\text { gather evidence } \\
\text { and data to test the } \\
\text { hypotheses; }(25 \%)\end{array}$ & $\begin{array}{l}\text { All hypotheses } \\
\text { were thoroughly } \\
\text { examined with } \\
\text { additional } \\
\text { evidence and } \\
\text { data. }\end{array}$ & $\begin{array}{c}\text { Most } \\
\text { hypotheses } \\
\text { were thoroughly } \\
\text { examined with } \\
\text { additional } \\
\text { evidence and } \\
\text { data. }\end{array}$ & $\begin{array}{c}\text { Some } \\
\text { hypotheses } \\
\text { were thoroughly } \\
\text { examined with } \\
\text { additional } \\
\text { evidence and } \\
\text { data. }\end{array}$ & $\begin{array}{l}\text { No hypothesis } \\
\text { was thoroughly } \\
\text { examined with } \\
\text { additional } \\
\text { evidence and } \\
\text { data. }\end{array}$ \\
\hline $\begin{array}{l}\text { Form conclusions } \\
\text { and execute } \\
\text { solutions. } \\
(25 \%)\end{array}$ & $\begin{array}{l}\text { A sound } \\
\text { conclusion was } \\
\text { reached and the } \\
\text { solution was } \\
\text { executed } \\
\text { successfully. }\end{array}$ & $\begin{array}{c}\text { A fairly } \\
\text { reasonable } \\
\text { conclusion was } \\
\text { reached but the } \\
\text { solution was } \\
\text { executed with } \\
\text { some difficulty. }\end{array}$ & $\begin{array}{l}\text { A conclusion } \\
\text { was reached } \\
\text { with significant } \\
\text { error and the } \\
\text { solution was } \\
\text { executed } \\
\text { without success. }\end{array}$ & $\begin{array}{l}\text { No meaningful } \\
\text { conclusion was } \\
\text { reached and no } \\
\text { attempt at } \\
\text { solution was } \\
\text { executed. }\end{array}$ \\
\hline
\end{tabular}

The main responsibilities of the lab instructors related to this project are to:

- Conduct mini-lectures on critical thinking and its application in circuit troubleshooting; 
- Explicitly showcase critical thinking in their demonstration of troubleshooting procedures;

- Evaluate students' critical thinking skills according to the given rubric;

- Provide feedback in terms of how students can improve their circuit troubleshooting by applying critical thinking.

\section{Student Performance Evaluation}

Three troubleshooting exercises were performed throughout the semester. For each exercise, students were required to write individual reports that were evaluated according to the rubric discussed above. Each report was graded on a 40-point scale with 10 points for each performance indicator in the rubric.

A total of 66 students were enrolled in five lab sections taught by two different lab instructors. Of these 66 students, $42(63.6 \%)$ submitted all three troubleshooting reports. Of these 42 students, 20 (47.6\%) showed improvement in their scores from the first to the third assignment. Furthermore, 16 (38.1\%) showed significant improvement (greater than 10\%) in these same assignments.

While these results are encouraging because a large portion of the students who completed all activities and assignments showed improvement in their troubleshooting report grades, the assessment method needs to be examined and improved for future implementations. In this study, the grades for the troubleshooting reports had the same weight as the traditional lab reports. As a result, students may not have been fully invested in submitting a well-written report, particularly at the end of the semester when most of their grade had already been determined. Furthermore, their troubleshooting skills were assessed based on a written report and students with poor writing skills may have had lower grades which did not reflect their true analytical abilities. These effects may be mitigated by using a different type of assessment, such as quizzes or practical exams with greater weight in the overall grade. With improved assessment method, we will not only be able to better gauge the effectiveness of the troubleshooting exercises, but also better motivate students to learn and improve their critical thinking and troubleshooting skills.

\section{Student Feedback}

At the beginning of the spring 2018 semester, a survey was distributed to students in the AC electric circuits lab (the follow-up course to DC electric circuits lab). Of these students, only the ones who completed the DC electric circuits lab during the fall 2017 semester completed the survey, i.e. students who took DC electric circuits in another semester or at another institution did not take part in the survey. The survey was given at this time so that the students knew their grades and had time to reflect on their experience during the winter break, rather than during their busiest time at the end of the fall semester. However, this timing introduced two issues with survey results. First, the surveyed population did not include students who received a grade lower than C- in the DC electric circuits course because that is the minimum prerequisite grade needed for the AC electric circuits course. Second, some students from the DC electric circuits course were not surveyed because they did not take the AC circuits course in Spring 2018 or 
were absent when the survey was given. As a result, of the 66 students who participated in the troubleshooting exercises, 30 completed the survey. The surveys were distributed in paper format during either the first or the second week of the AC electric circuits labs and students completed them anonymously. There were seven questions (Q1-Q7) based on the Likert scale and three open-ended questions (Q8-Q10) listed below.

Q1. Troubleshooting exercises helped me improve my troubleshooting skills.

Q2. Troubleshooting exercises helped me improve my critical thinking skills.

Q3. Troubleshooting exercises helped me perform better in other labs and projects in this course.

Q4. I enjoy troubleshooting exercises.

Q5. Troubleshooting exercises are more challenging than typical labs.

Q6. Troubleshooting exercises helped me better understand the theory introduced in the lectures.

Q7. Troubleshooting exercises helped me perform better in other courses.

Q8. Please describe your favorite thing about the troubleshooting exercises.

Q9. Please describe a memorable moment during the troubleshooting sessions.

Q10. Please provide suggestions to help us make improvements.

Table 3 and Figure 4 provide the results of the survey. From these results, it is clear that the students overwhelmingly agree that the troubleshooting exercises helped improve their troubleshooting skills and critical thinking skills. As the questions became less specific to the application, their responses were less positive. The lowest agreement was in questions related to the enjoyment of the troubleshooting exercise and whether the exercises help them perform better in other courses.

Table 3: Summary of Student Survey Responses

\begin{tabular}{|c|c|c|c|c|c|}
\hline & \multicolumn{5}{|c|}{ Neither } \\
\hline & $\begin{array}{l}\text { Strongly } \\
\text { Disagree }\end{array}$ & Disagree & $\begin{array}{c}\text { Agree } \\
\text { Nor } \\
\text { Disagree }\end{array}$ & Agree & $\begin{array}{c}\text { Strongly } \\
\text { Agree }\end{array}$ \\
\hline $\begin{array}{l}\text { Q1. Troubleshooting exercises helped } \\
\text { me improve my troubleshooting skills. }\end{array}$ & $0 \%$ & $6.7 \%$ & $6.7 \%$ & $63.3 \%$ & $23.3 \%$ \\
\hline $\begin{array}{l}\text { Q2. Troubleshooting exercises helped } \\
\text { me improve my critical thinking } \\
\text { skills. }\end{array}$ & $0 \%$ & $6.7 \%$ & $10.0 \%$ & $63.3 \%$ & $20.0 \%$ \\
\hline $\begin{array}{l}\text { Q3. Troubleshooting exercises helped } \\
\text { me perform better in other labs and } \\
\text { projects in this course. }\end{array}$ & $3.3 \%$ & $10.0 \%$ & $33.3 \%$ & $43.3 \%$ & $10.0 \%$ \\
\hline Q4. I enjoy troubleshooting exercises. & $17.2 \%$ & $6.9 \%$ & $34.5 \%$ & $34.5 \%$ & $6.9 \%$ \\
\hline $\begin{array}{l}\text { Q5. Troubleshooting exercises are } \\
\text { more challenging than typical labs. }\end{array}$ & $6.9 \%$ & $20.7 \%$ & $20.7 \%$ & $24.1 \%$ & $27.6 \%$ \\
\hline $\begin{array}{l}\text { Q6. Troubleshooting exercises helped } \\
\text { me better understand the theory } \\
\text { introduced in the lectures. }\end{array}$ & $3.3 \%$ & $13.3 \%$ & $26.7 \%$ & $40.0 \%$ & $16.7 \%$ \\
\hline $\begin{array}{l}\text { Q7. Troubleshooting exercises helped } \\
\text { me perform better in other courses. }\end{array}$ & $6.7 \%$ & $26.7 \%$ & $56.7 \%$ & $6.7 \%$ & $3.3 \%$ \\
\hline
\end{tabular}



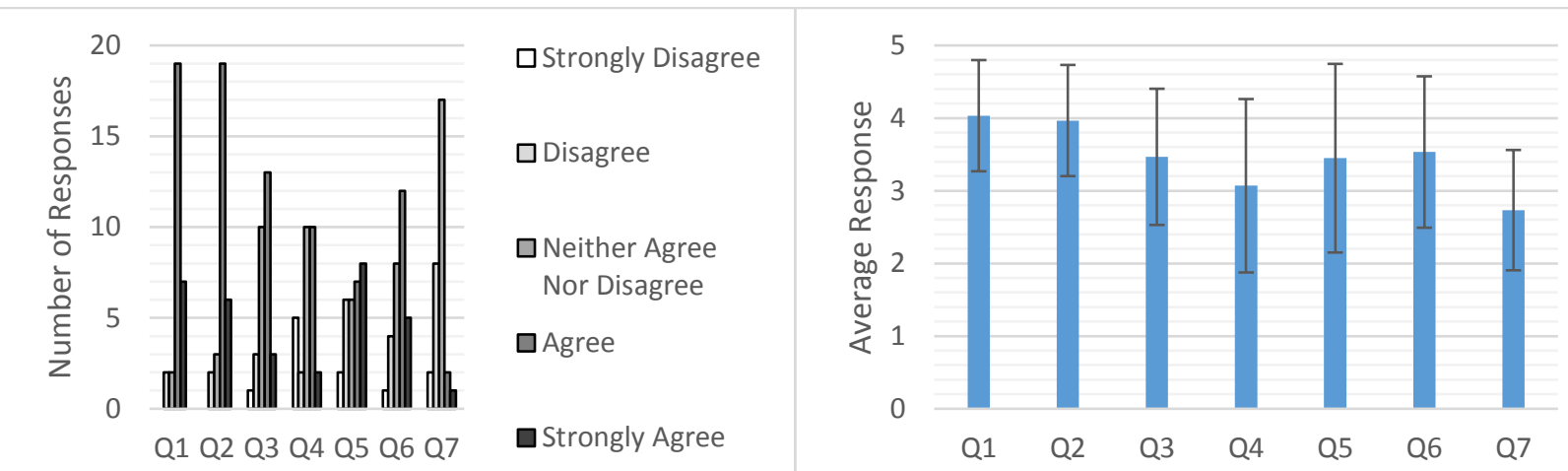

Figure 4: Histogram of survey responses (left) and average response to each survey question (right).

Tables 4 and 5 show correlations between student responses to the seven Likert-scale questions. The values in Table 4 are the Pearson correlation coefficients. These values are a measure of the linear correlation between question responses and range from -1 to +1 , where values of -1 and +1 indicate perfect negative and perfect positive correlations respectively and 0 indicates no correlation. Table 5 shows qualitatively the strength and direction for each correlation by characterizing them as strong positive $(+++)$, moderate positive $(++)$, weak positive $(+)$, none $(0)$, weak negative (-), moderate negative (--), and strong negative (---). The central values for weak, moderate, and strong correlations were $0.3,0.5$, and 0.7 respectively. In each table, darker gray shading indicates the stronger correlations.

Table 4: Correlation Values for Each Pair of Questions

\begin{tabular}{|c|c|c|c|c|c|c|c|}
\hline & $Q 1$ & $Q 2$ & $Q 3$ & $Q 4$ & $Q 5$ & $Q 6$ & $Q 7$ \\
\hline Q1 & 1 & & & & & & \\
\hline Q2 & 0.650 & 1 & & & & & \\
\hline Q3 & 0.603 & 0.455 & 1 & & & & \\
\hline Q4 & 0.766 & 0.396 & 0.755 & 1 & & & \\
\hline Q5 & -0.299 & 0.016 & -0.501 & -0.665 & 1 & & \\
\hline Q6 & 0.280 & 0.413 & 0.549 & 0.406 & -0.305 & 1 & \\
\hline Q7 & 0.396 & 0.367 & 0.611 & 0.522 & -0.341 & 0.691 & 1 \\
\hline
\end{tabular}

Table 5: Strength and Direction of Correlation for Each Pair of Questions

\begin{tabular}{cccccccc}
\hline & $Q 1$ & $Q 2$ & $Q 3$ & $Q 4$ & $Q 5$ & $Q 6$ & $Q 7$ \\
\hline Q1 & 1 & & & & & & \\
Q2 & +++ & 1 & & & & & \\
Q3 & +++ & ++ & 1 & & & & \\
Q4 & +++ & + & +++ & 1 & & & \\
Q5 & - & 0 & -- & --- & 1 & & \\
Q6 & + & ++ & ++ & ++ & - & 1 & \\
Q7 & + & + & +++ & ++ & - & +++ & 1 \\
\hline
\end{tabular}


The plots of responses to three pairs of questions are shown in Figures 5 and 6. For each graph, each individual response to the questions is plotted as a circular point and the area of the circular points is proportional to the number of students who responded with those values of the Likert scale. For example, the largest number of students responded with a "4" for Q1 and "3" for Q4 and this is seen as the largest circle in the left plot in Figure 5. The line on each graph is the line of best fit.
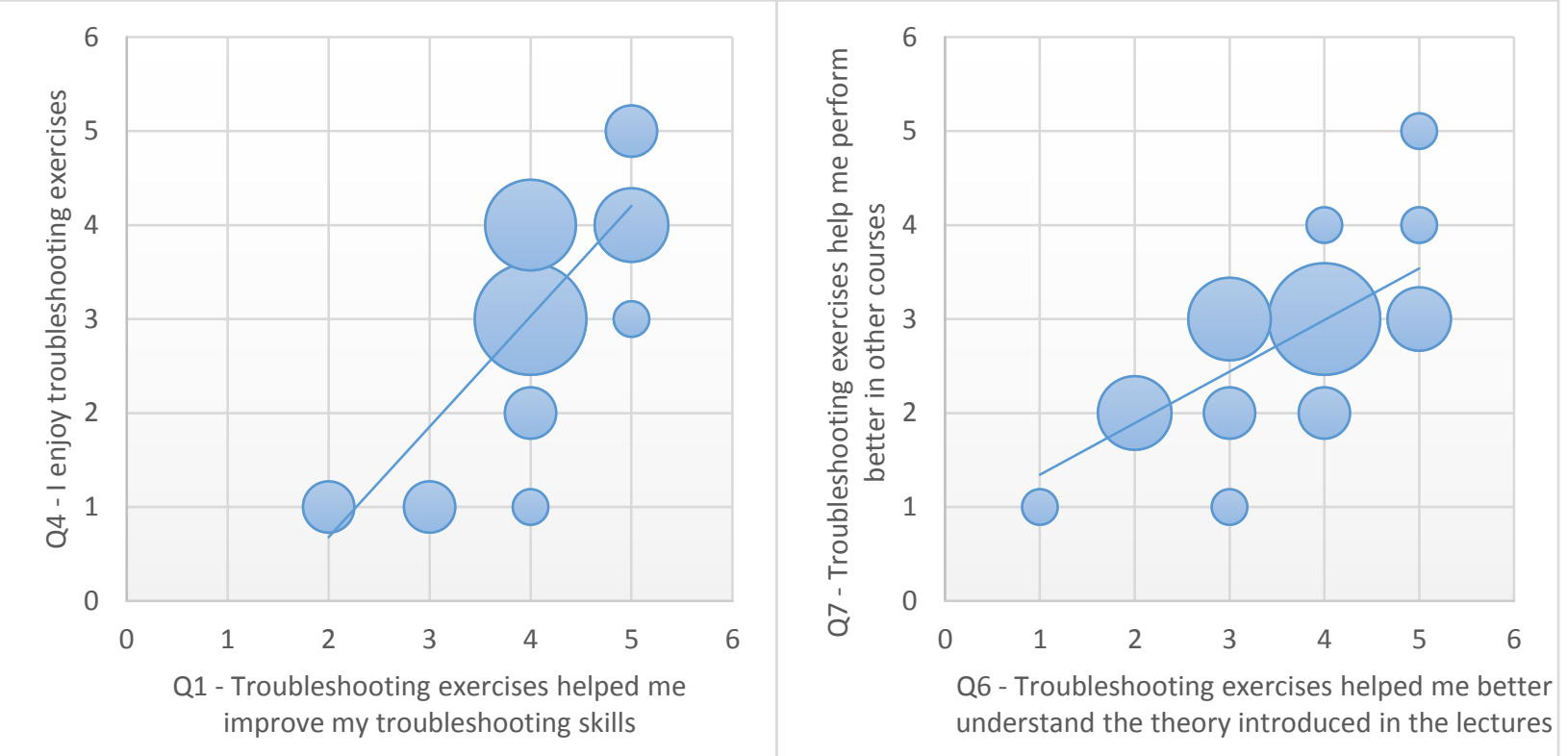

Figure 5: Strong positive correlations between $Q 1 \& Q 4$ (left) and $Q 6 \& Q 7$ (right).

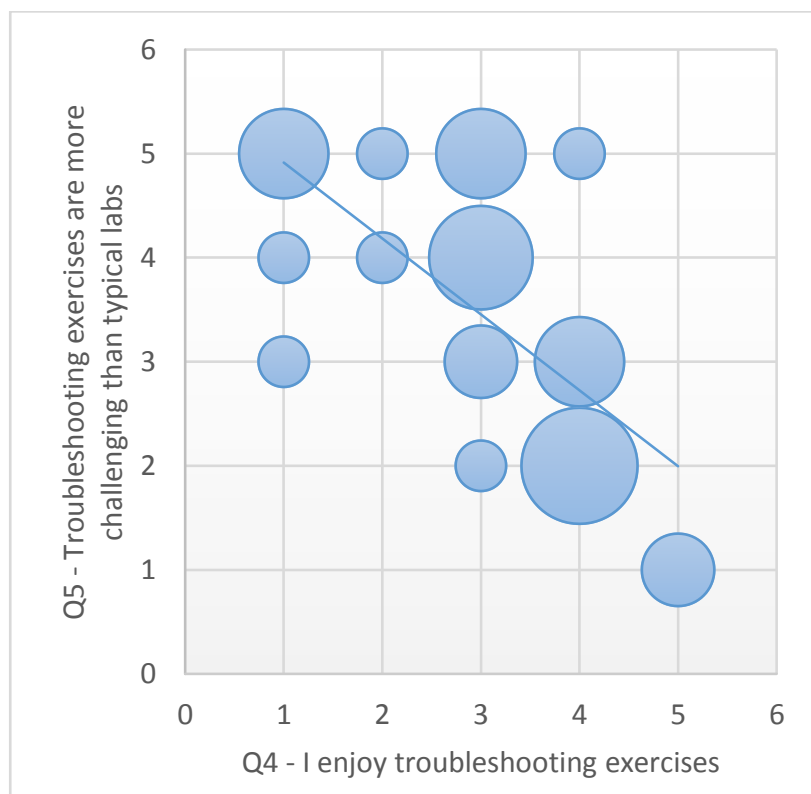

Figure 6: Strong negative correlation between $Q 4 \& Q 5$. 
Several observations can be made from the correlation data of the Likert scale questions:

- The strongest correlation is seen between Q1 and Q4. The students who thought the troubleshooting exercises improved their troubleshooting skills were likely to also enjoy the troubleshooting exercises. This strong correlation shows that their learning experience and attitude goes hand-in-hand and they are more likely to gain knowledge from an exercise if they enjoy it.

- Another strong positive correlation is between Q6 and Q7. The students who tied their troubleshooting skills to the DC electric circuit theory were also able to transfer it to other courses. This correlation seems to indicate that if students are able to make the initial connection to the theory in the course, they may be able to transfer it on their own to other courses.

- There was a strong negative correlation between Q4 and Q5. Students who found the troubleshooting exercises more challenging are more likely to be the same ones who did not enjoy them, and vice versa. Coupled with Q1, this indicates that the exercises need to be thoughtfully crafted so they are not so challenging that students cannot complete them, but not too simple that students do not see their value.

Summary of student feedback in the open-ended questions:

In question 8 , we asked students to describe their favorite thing about the troubleshooting exercises. One notable frequent common response is about the sense of satisfaction or relief related to finally being able to figure out the fault in the circuit and fix it. Another frequent common response is related to the unstructured nature of the troubleshooting exercises in which procedures are not set in advance and students have to "think for themselves."

In question 9, we asked students to describe a memorable moment during the troubleshooting sessions. One frequent common response is related to the unexpected nature of the faults: a broken wire disguised under electric tapes. Some other frequent common responses are related to the challenges they have encountered or mistakes they made during the process.

In question 10, we asked students to provide suggestions to help us make improvements. Most students who considered the troubleshooting exercises more challenging asked for more hints and easier exercises, while most students who considered the troubleshooting exercises not as challenging asked for more challenging exercises.

\section{Instructor Feedback}

Summary of lab instructors' observations and feedback:

- Students are more enthusiastic and engaged in troubleshooting sessions compared to regular lab sessions.

- Students are more communicative with each other and with the instructor. Instead of following strict steps listed in the lab manual, students are encouraged to discover the many possibilities themselves.

- During the last and most difficult troubleshooting session, some students feel more pressure and stress when they cannot manage to successfully troubleshoot and fix the faulty circuit, but they also feel more rewarding when they do finally succeed. They 
seem very proud of the fact they manage to finally fix the circuits. This might be beneficial to help students develop grit and resilience.

- For lab instructors, the troubleshooting sessions require much heavier workload in terms of designing and building faulty circuits before class, answering non-stop questions during the lab, and grading troubleshooting prelab work and lab reports. Students have more questions especially when they mistakenly think that they have solved the circuit. The instructors would then ask students probing questions in terms of whether they have investigated a number of possibilities, advise the students to document the measurements, and assess the validity of the measured values.

- There is definitely improvement in students' troubleshooting and critical thinking abilities, but it would be crucial to have more related material in lectures in order to have more significant improvement. Students need to be exposed to the concept with more repetition.

- The prelab assignments are very helpful in terms encouraging students to think about all the possible scenarios before taking action. Prelab assignments should be introduced earlier so that the due date for the prelab reports can also be pushed earlier which allows the lab instructors time to review them before the actual troubleshooting sessions. This will give instructors more insight into students' thinking and better facilitate their learning. Prelab quizzes might also be a good idea to encourage students to spend more efforts on their prelab work.

- One of the lab instructors also taught the same labs last fall semester. He observes that this cohort of students seem to be better students compared to those of the past several years: more enthusiastic, more engaged, and more communicative. This difference might be a positive impact due to the introduction of the critical thinking/troubleshooting exercises.

- Students complained about the lack of synchrony between lecture content and lab content. This may have had significant negative impact on students' learning experience. It would be a priority for future improvement.

- Some students who finish the troubleshooting exercises very quickly in class might not have properly documented the procedures and measurements. Some students do not put in enough effort in generating proper reports even though they have successfully completed the troubleshooting exercises in class. It would be crucial to stress to students the importance of the writing assignments for future efforts.

\section{Conclusion and Future Work}

Students' troubleshooting skills were assessed using their troubleshooting reports. According to the instructors' evaluation of students' troubleshooting reports, about $38 \%$ of students who completed all troubleshooting activities and assignments showed significant improvement in their troubleshooting reports. According to the student surveys, about $86 \%$ of students agree or strongly agree that troubleshooting exercises helped them improve their troubleshooting skills; about $83 \%$ of students agree or strongly agree that troubleshooting exercises helped them improve their critical thinking skills; about $53 \%$ of students agree or strongly agree that troubleshooting exercises helped them perform better in other labs and projects; about $56 \%$ of students agree or strongly agree that troubleshooting exercises helped them better understand the theory introduced in the lectures. 
Summary for future work:

- Newly-designed troubleshooting exercises are introduced in AC electric circuits (the follow-up course to DC electric circuits) starting in spring semester 2018.

- In addition to troubleshooting reports, a more direct assessment method, such as quizzes or practical exams with greater weight in the overall grade, will be introduced to better assess students' troubleshooting skills.

- To allow students to make more significant improvement, troubleshooting and critical thinking material should be introduced in lectures as well.

- More opportunities need to be created for students to connect critical thinking with aspects outside of their academic life.

- Regular meetings will be conducted throughout the semester among all lecture and lab instructors to ensure synchrony between lecture and lab content.

- Standard PCB boards can be mass-produced and can be used to reduce instructors' workload in terms of building faulty circuits and allow for more sophisticated and demonstrative examples.

\section{Reference:}

[1] "It Takes More Than A Major: Employer Priorities for College Learning and Student Success," An Online Survey Among Employers Conducted On Behalf Of: The Association Of American Colleges And Universities By Hart Research Associates, April 2013. Available https://www.aacu.org/sites/default/files/files/LEAP/2013_EmployerSurvey.pdf

[2] M. Scriven \& R. Paul, "Defining Critical Thinking: A draft statement for the National Council for Excellence in Critical Thinking," [On-line] 1996. Available http://www.criticalthinking.org/University/univlibrary/library.nclk

[3] C. Greco, J. Reasoner, D. Bullock, C. Castillo, P. Buford, G. Richards, "Efficacy of Lab Reports for Electric Circuits Laboratory Assessment," ASEE Annual Conference June 26-29 2011, Vancouver, British Columbia, Canada

[4] D. M. Buchla, "Experiments in Basic Circuits: Theory and Applications," $9^{\text {th }}$ edition, 2009, Pearson 